\title{
Gender Difference in of Organisational Behaviour (OCB) and Motives Underlying OCB
}

\author{
Anu Priya Punia* and Radhey Shyam \\ Department of Psychology, M.D. University, India
}

Submission: May 09, 2017; Published: May 31, 2017

*Corresponding author: Anu Priya Punia, Department of Psychology, M.D. University, Rohtak, India, Email: anupriyapunia@gmail.com

\begin{abstract}
Do men and women really differ in the kind of behaviour they display? Do their motives for indulging in certain behaviours differ from one another? This Gender debate has been a subject for speculation for the behaviourist. In today's competitive world one needs an edge over another to succeed; the organisations especially like to understand aspects that will enable them to retain this edge. Human resource is one such area that if utilized to its true potential can ascertain wonderful result, however in order to so the management needs to understand their workforce. Understanding workforce also entails understanding the basic gender differences underlying behaviour. The current study focuses on understanding whether the female and male employees in an organisation differ in displaying Organisational Citizenship Behaviour (OCB) and whether their motives for indulging in this non mandatory behaviour differ as well. The study was conducted on 140 employees (70 Females, 70 Males) from the Information Technology sector.
\end{abstract}

Keywords: Gender difference; OCB; Motives; Organisation

\section{Introduction}

"People's behaviour makes sense if you think about it in terms of their goals, needs and motives" Thomas Mann

Psychology is the science of behaviour, understanding "why aspect of behaviour" is of utmost importance. It is a basic human need to understand what motivates an individual to act in a certain manner. Organisational Psychologists acknowledge this essential aspect and hence are focused on understanding what drives people and how can these motives be understood to facilitate efficiency of workforce. One such behaviour that is extensively studied within an organisation is Organisational Citizenship Behaviour (OCB). OCB may be understood as "Individual Behaviour that is discretionary, not directly or explicitly recognised by the formal reward system and that in the aggregate promotes the effective functioning of the organisation" [1]. This means that these behaviours are not mandated or a requisite for a job but are rather voluntarily indulged in by employees. Upon reflection the question that needed answering was why certain employees felt compelled to indulge in behaviours which were neither acknowledged nor rewarded directly by the organisation. Rioux \& Penner [2] were the first to study the possible motives which might explain why OCB occurred. This phenomenon was further studied by a number of researchers [3]; Finkelstein [4]. Despite numerous studies it is essential to know what the motives are and do they vary from individual to individual. The current study aims at understanding whether Gender plays a role in the extent to which an employee exhibits such voluntary behaviours and whether males and females differ in motives underlying such behaviours.

\section{Organisational Citizenship Behaviour (OCB)}

In Organisational \& Industrial Psychology, Organisational Citizenship Behaviour is understood as an individual's elective undertaking within an organisation that is in no way a part of their ordained tasks. This concept of OCB has been researched for over three decades now. The attempts to understand this concept and relate it to other variables date back to early 1980's. Various researchers over the years have tried to delineate the dimensions of OCB. Over time a number of taxonomies pertaining to this concept came into being in order to comprehend these voluntary behaviours. The term "Organisational Citizenship Behaviour" was first introduced by Organ \& Bateman following which researchers have identified about thirty different forms of OCB. 
Organ, Near \& Smith (1983): These researchers with the help of factor analysis of 16 items measure of OCB and these were reduced to just two factors: a. Generalised Compliance (Conscientiousness), b. Altruism.

Organ (1988): Organ is the one who basically coined the term Organisational citizenship Behaviour. He then went on to give a five factor Model of OCB.

i. Altruism: This kind of behaviour refers to an innate tendency to help other without any expectation of reward or acknowledgement of any kind. For e.g. helping a co-worker with their workload.

ii. Conscientiousness: can be defined as exceeding minimum role requirement of an organisation [5]. It consists of cluster of behaviours like: adherence to rules and regulations of the company even when no one is watching.

iii. Sportsmanship: refers to not displaying any sort of negative behaviour when things do not turned as planned. A sporty individual is ready to go with the flow and does not get perturbed easily if situations at the workplace seem less than desirable.

iv. Courtesy: Courteous behaviour is one where an individual is polite and considerate towards the feelings and needs of others. These people indulge in behaviours that minimise work related problems like informing peers regarding meeting schedules or any change in them.

v. Civic Virtue: This refers to employee's internal concern and active attention to the existence of the organisation [6]. For e.g. participating proactively in company meetings and being active in works related to the betterment of the organisation. Almost all of the further models of OCB are variants of Organ's dimensions.

Lin (1991): Illustrated six dimensional model of OCB, his dimensions were: 1)Self- Improvement, 2) Harmony, 3)Righteousness, 4)Discipline, 5)Identification with the organisation, 6)Assistance to Colleagues.

Anderson and Williams (1991): Based their approach on the directed behaviour. OCB was divided into two constructs by them: OCB-I: People indulging in these behaviours directed their behaviour towards helping other co- workers. It is directed towards other individuals within the organisation e.g. helping newly appointed people. OCB-O: Exhibits behaviours oriented towards the company like participating in pro organisational activities [7].

Van Dyne, Dieneschand Graham (1994): They delineated three dimensions of OCB: Loyalty: pertains to preservation of community and working towards its betterment for common good. Participation: This refers to involving oneself in community affairs. Obedience: This refers to respecting the order and structure of the organisation [8].
Podsakoff et al. (2000): Keeping in mind all the above dimensions these researchers boiled down OCB to seven dimensions. A) Individual Initiative which means the readiness of an individual to go beyond expected level of duties to settle issues. B) Organisational Compliance refers to abiding by and obeying the policies and procedures of the Organisation. C) Organisational Loyalty refers to employees promoting the cause of their organisation and being committed to their company even in adverse conditions. D) Sportsmanship refers to the ability to stay positive and not complain even under unfavourable circumstances. E) Self Development refers to the personal initiative undertaken by an employee to enhance their knowledge and skill sets in order to perform better. F) Civic virtue consists of responsible behaviour of an individual in an organisational set up.

As is obvious from above, some of the dimensions overlap and are not really adequate to understand OCB. The researcher has used Organ's five dimensions to understand the gender difference among the OCB displayed by employees.

\section{OCB Motives}

The understanding of motives is essential in organisational sector as the reward system primarily depends upon what drives an individual. These motives can be intrinsic or extrinsic, individual oriented to group oriented. Psychology as a whole is a rather complex science wherein each individual behaves in a particular manner and underlying intent cannot be generalised. Anyone can do the same work with different intent therefore the outcomes may serve different needs in different people. In this study we are trying to understand the motives that drive people to perform organisational behaviour and if at all there is any difference in these motives based upon the gender of the employee performing this behaviour. In order to do so we must first understand both Organisational citizenship behaviour (OCB) and motives and find the common motives that underlie these behaviours.

Though researchers such as Bolino did delve into the role of motives it was Penner and his co researchers who first addressed this concept from a functional aspect. The basis of this functional perspective is a simple trait "that people engage in certain behaviour (e.g., OCB) because such actions serve some primary need of that individual". In other words behaving in such a manner serves a purpose [9]. For instance one person may help another for it makes them look good, another person however may help a co-worker simply out of goodness of heart or in an altruistic manner. Despite the fact, that these people performed similar behaviour their reasons to do so vary. A major part of the support for a practicable approach to OCB comes from the related phenomena of "volunteerism". Hanson in 1991 defined Volunteerism as "formal planned helping" which involves helping others through service organisations such as churches, schools, hospitals etc. This behaviour is very similar to citizenship behaviour: a) both are long term $\mathrm{b}$ ) both are carefully 
thought and planned c) their context is an organisation d) these both refer to decision to help made by a person. The researchers applying a functional approach have strongly supported that individuals vary about reasons for volunteering based on their needs. Hence such researches act as springboard for work on OCB and Motives. Rioux and Penner [2] delineated three primary OCB motives:

Organisational Concern: This focuses on display of OCB by an employee motivated by the need to display commitment to the organisation. This motive enables an employee to increase their knowledge base and also enhance work experience [10].

Prosocial Values: This pertains to display of OCB with a desire to help others and be recognised by them. This motive is important for people with a strong need of approval and who believe in the importance of maintaining relationships.

Impression Management: This refers to engaging in OCB with a desire to either gain materialistic rewards or avoid negative evaluation by others within the organisation. This behaviour is usually displayed by people with a higher need for acceptance. These people are overly concerned about others opinion of them. Thus they wish to avoid being viewed as lazy or irresponsible by displaying OCB.

These motives have been found to correlate strongly with different dimensions of OCB. Overall researchers tend to suggest that these motives may in effect play a pivotal role in the prediction of OCB.

\section{Gender Difference}

Lately a lot of emphasis is being laid on how Gender impacts different constructs, in the same vein the researcher in this current study has tried to understand the role of gender in display of OCB and its underlying motives. Researchers have indicated at a possibility of subtle discriminations exists when men and women are rated for appraisal based on their display of OCB [11]. It's a common assumption that both genders display different types of OCB. Gender influences how an individual's behaviour is interpreted. If thought of as a personal characteristic then gender influences how an employee might view their workplace and it also impacts their attitude towards their co- workers. Gender also tends to affect how an individual connects with co-workers who tend to render social support, opportunities \& information [12]. Research suggests that helping behaviour is central to female gender stereotype perception that purports that women are inherently nurturing and more socially oriented therefore women are expected to be higher in altruism, whereas behaviours associated with male gender stereotype include participation in various organisational activity and being concerned about the parent organisation, these are typical traits of one high in civic virtue and sportsmanship. Not many studies focus on how gender impacts OCB and that leads to a research
Gap. The current study intends to study if there actually exists any difference in OCB and its motives based on the gender of the employee displaying such behaviour.

\section{Objectives}

a. To assess whether there is a difference in female and male employees in display of Organisational Citizenship Behaviour (OCB)

b. To assess whether there is a difference in female and male employees in display of motives underlying OCB.

\section{Hypotheses}

a. There will be a difference in OCB displayed by female and male employees.

b. There will be a difference in underlying motives of OCB performed by female and male employees.

\section{Method}

Sample: A sample of 140 employees (70 females \& 70 males) was selected from information technology sector. These employees were mid-level managers falling in the age range of 28- 32 years, with a work experience of at least 3 years and not less than one year within the current organisation. The sample was selected following non - random purposive sampling basis.

\section{Tools}

Organisational Citizenship Behaviour (OCB): A modified version of the scales developed by Podsakoff \& Mackenzie [6] was used to measure OCB. It consists of 24 items, and measures all five dimensions of OCB identified by Organ (1988); Altruism, Conscientiousness, Sportsmanship, Courtesy \& Civic Virtue. Respondents were asked to indicate the degree to which they agreed with each item using a seven-point likert scale. This scale ranged from (1) "strongly disagree" to (7) "strongly agree". Numerous studies using the scale have shown that the measure possess good validity as well as acceptable internal consistency reliability $[6,13]$.

Citizenship Motives Scale: Employee motives for engaging in OCB were measured using Rioux \& Penner's [2] Citizenship Motives Scale (CMS). This scale consisted of 30 items, and measured all three of the motives for engaging in OCB: (1) Pro social values (2) Organisational Concern and (3) Impression Management. Respondents were asked to rate on a scale ranging from "not at all important" to "extremely important" how influential was each item in their decision to engage in OCB. Psychometric evidence provided by Rioux \& Penner [2] reports internal consistency reliability above .80 and test-retest reliabilities for each factor .70 .

\section{Results and Discussion}

(Table 1) The comparison between female and male employee in Table 1 shows that the difference in certain 
dimensions of OCB performed by them. Results show that $\mathrm{t}$ value on conscientiousness is 1.22 and it is non- significant, t-value of Altruism is 1.05 and this too is non- significant. However, when we compare both genders on dimensions such as Sportsmanship ( $\mathrm{t}$ - value $2.86, \mathrm{p}<.01$ ), Civic Virtue ( $\mathrm{t}$ - value,
$4.14, \mathrm{p}<.01$ ), Courtesy (t- value, 3.47,p <.01), and Total Score of OCB (t-value, 5.33,p <.01) the difference among female and male employees is significant and hence our Hypothesis (a) is accepted that there indeed is a difference in display of OCB by female and male employees (Table 2).

Table 1: Mean, Std. Deviation and t-value of female and male employees on OCB scale.

\begin{tabular}{|c|c|c|c|c|c|c|}
\hline \multirow{2}{*}{ S No. } & \multirow{2}{*}{$\begin{array}{l}\text { Dimensions of } \\
\text { OCB }\end{array}$} & \multicolumn{2}{|c|}{ Females } & \multicolumn{2}{|c|}{ Males } & \multirow{2}{*}{ t-value } \\
\hline & & Mean & S.D. & Mean & S.D. & \\
\hline 1. & Conscientiousness & 31.84 & 1.49 & 32.14 & 1.41 & $1.22 \mathrm{~ns}$ \\
\hline 2. & Altruism & 31.37 & 1.45 & 31.63 & 1.46 & $1.05 \mathrm{~ns}$ \\
\hline 3. & Sportsmanship & 31.34 & 1.74 & 32.10 & 1.36 & $2.86^{* *}$ \\
\hline 4. & Civic Virtue & 24.80 & 1.62 & 25.96 & 1.69 & $4.14^{* *}$ \\
\hline 5. & Courtesy & 31.36 & 1.43 & 32.27 & 1.68 & $3.47^{* *}$ \\
\hline 6. & Total OCB & 1.51 & 3.74 & 1.54 & 3.78 & $5.33^{* *}$ \\
\hline
\end{tabular}

ns = Non- Significant ${ }^{* *}=$ Significant at 0.05 level.

Table 2: Mean, Std. Deviation and t- value of female and male employees on Citizenship Motives Scale (CMS).

\begin{tabular}{|c|c|c|c|c|c|c|}
\hline \multirow{2}{*}{ S. No. } & \multirow{2}{*}{ Motives } & \multicolumn{2}{|c|}{ Females } & \multicolumn{2}{|c|}{ Males } & \multirow{2}{*}{ t-value } \\
\hline & & Mean & S.D. & Mean & S.D. & \\
\hline 1. & $\begin{array}{l}\text { Organisational } \\
\text { Concern }\end{array}$ & 44.77 & 3.88 & 45.43 & 3.88 & $.99 \mathrm{~ns}$ \\
\hline 2. & Prosocial Values & 44.87 & 3.63 & 43.40 & 3.78 & $2.35^{* *}$ \\
\hline 3. & $\begin{array}{l}\text { Impression } \\
\text { Management }\end{array}$ & 39.87 & 4.98 & 41.89 & 3.58 & $2.75^{* *}$ \\
\hline
\end{tabular}

ns = Non- Significant $;{ }^{* *}=$ Significant at 0.05 level.

The comparison between female and male employees in Table 2 shows that there is a significant difference in 2 out of 3 motives underlying OCB. Results show that while difference in Organisational concern (t- value, .99ns) is non-significant the other two dimensions namely: Prosocial values ( $\mathrm{t}$ - value, $2.35, \mathrm{p}<.01$ ) and Impression Management ( $\mathrm{t}$ - value, 2.75,p <.01) differ significantly. Thus this table proves Hypothesis (b) to be correct that there is a difference in motives underlying OCB of female and male employees.

The purpose of this study was to investigate if females and males differ in their display of organisational citizenship behaviour (OCB) and do the motives for indulging in these nonmandatory behaviours differ as well. Table 1 indicates that men and women do not differ substantially in display of dimensions such as Conscientiousness and Altruism, the general assumption of gender stereotype is that women are inherently nurturing and helping out in an organisational set up is considered a somewhat 'requisite' behaviour for women owing to their inherent nurturing nature. Women are not seen as doing something out of the ordinary if they indulge in altruistic behaviour but are penalised if they do not act so. But if we notice the dimensions such as civic virtue, courtesy and sportsmanship the difference between men and women is significant. Men tend to display this behaviour more than women. The prescriptive gender stereotype views behaviours such as civic virtue and sportsmanship as inherently male behaviours but the twist is that even if this behaviour is performed by men it is viewed as non- mandatory behaviour and hence men tend to benefit from display of such behaviour. This reward system seems to put women at a disadvantage as they do not benefit from display of such behaviours but are penalised for not displaying them. Hence this leads us to accept Hypothesis (a) that there is a difference in OCB displayed by male and female employees.

The second hypothesis suggests that men and women differ in their motives underlying OCB. If we look at Table 2 it is evident that while both the genders do not differ significantly on the motive of organisational concern, they do however differ significantly on Prosocial Motives and Impression Management. As per the findings women are more motivated by Prosocial Values and men are higher on Impression Management. These results too are in line with the prescriptive gender stereotypes that women are innately helpful and nurturing in nature and hence are motivated by a need to help others and a need for acceptance. Men however are higher in need for approval and wish to avoid negative evaluation as well as gain materialistic rewards and hence are motivated by a need to impress. The results obtained after analysis of the data are in line with the initial assumption that there indeed is a difference between males and females in the kind of OCB displayed and their underlying motives too differ.

\section{Conclusion}

The purpose of the study was to ascertain whether males and females differ in display of OCB and if their motives for doing 
so are different as well. From the current study it is evident that there is a difference between the kind of behaviour displayed and the motivation to do so. The reason of this difference may be attributed to prescriptive gender stereotype that leads to a certain biasing in the reward system that is followed by the organisations. This prescriptive behaviour leads to women being disadvantaged i.e. no special reward for displaying OCB but being penalised for not indulging in these dimensions. Women are seen to display less OCB as compared to men and are higher in Prosocial motive which can be attributed to their inherent helpful nature where else men display higher OCB as they are rewarded for such behaviour and their motive for this seems to be garner materialistic rewards and avoid negative evaluation. More research needs to be carried out in this context so as to encourage a change in the organisational set up to enhance betterment of the organisation.

\section{References}

1. Rioux SM, Penner LA (1998) Assessing individual motives for engaging in organizational citizenship behaviors: A functional approach. Unpublished Dissertation, University of South Florida, Tampa, Florida, USA.

2. Rioux, S.M., \& Penner, L.A. (2001) The causes of organizational citizenship behavior: A motivational analysis. J Appl Psychol 86(6): 1306-1314.

3. Berber A, Rofcanin Y (2012) Investigation of Organisational Citizenship Behaviour Construct: A Framework for Antecedents and Consequences. International Journal of Business and Social Research 2(4): 195-205.

4. Penner LA, Finkelstein MA (1998) Dispositional and structural determinants of volunteerism. Journal of Personality and Social Psychology74(2): 525-537.

5. Heilman ME, Chen JJ (2005) Same behaviour, different consequences: Reactions to Men's and Women's Altruistic citizenship behaviour. J Appl Psychol 90(3): 431-441.

6. Podsakoff PM, Mackenzie SB, Paine JB, Bachrach DG (2000) Organisational Citizenship Behaviours: A Critical Review of the Theoretical and Empirical Literature and Suggestions for Future Research. Journal of Management 26(3): 513-563.

7. Alizadeh Z, Darvishi S, Nazari K, Emami M (2012) Antecedents and Consequences of Organisational Citizenship Behaviour (OCB). Interdisciplinary Journal of Contemporary Research in Business 3: 494-502.

8. Van Dyne L, Cummings LL, McLean Parks JM (1995) Extra role behaviours: In pursuit of construct and definitional clarity (a bridge over muddied waters). Research in organisational behaviour. Greenwich, USA, JAI Press 17: 215-285.

9. Burgess D, Borgida E (1999) Who women are, who women should be: Descriptive and prescriptive gender stereotyping in sex discrimination. Psychology, Public Policy and Law 5(3): 665-692.

10. Rudman LA (1998) Self- promotion as a risk factor for women: The costs and benefits of counter-stereotypical impression management. J Pers Soc Psychol 74(3): 629-645.

11. Allen TD, Rush MC (1998) The effects of organisational citizenship behaviour on performance judgement: A field study and a laboratory experiment. J Appl Psychol 83(2): 247-260.

12. Kidder DL, McLean Parks J (2001) The good soldier: Who is (s)he? Journal of Organisational Behaviour 22(8): 939-959.

13. Tabassum R (2016) The study of relationship between dimensions of organisational citizenship behaviour and gender difference: A literature review. International Journal of Science Technology and Management 5(2): 300-308.

Your next submission with Juniper Publishers
will reach you the below assets
- Quality Editorial service
- Swift Peer Review
- Reprints availability
- E-prints Service
- Manuscript Podcast for convenient understanding
- Global attainment for your research
- Manuscript accessibility in different formats
( Pdf, E-pub, Full Text, Audio)
- Unceasing customer service
Track the below URL for one-step submission
https://juniperpublishers.com/online-submission.php

